\title{
En torno a la ejecución y liquidación del presupuesto de los entes locales
}

\author{
Juan Calvo Vérgez \\ Profesor Contratado Doctor de Derecho Financiero y Tributario. Universidad de Extremadura
}

Sumario: I. CONSIDERACIONES PREVIAS.-II. LA GESTIÓN DE LOS GASTOS PÚBLICOS. 1. Introducción. 2. Fases de ejecución de los presupuestos locales. A) Autorización del gasto. B) Disposición o compromiso del gasto. C) Reconocimiento de la obligación. D) Ordenación y ejecución del pago.-III. GESTIÓN DEL PRESUPUESTO DE INGRESOS.IV. LIQUIDACIÓN Y CIERRE DEL PRESUPUESTO LOCAL.

\section{CONSIDERACIONES PREVIAS}

Como es sabido la ejecución presupuestaria es objeto de regulación, con carácter general, en la Sección 3. ${ }^{a}$ del Capítulo VI ( «De la gestión presupuestaria») del Título II («De los Presupuestos Generales del Estado») de la Ley 47/2003, de 26 de noviembre, General Presupuestaria (arts. 73 a 80). Dentro de dicha Sección 3. ${ }^{\text {a }}$ se contiene una nítida diferenciación entre la ejecución del presupuesto de ingresos y la ejecución del presupuesto de gastos. Esta ejecución del presupuesto o gestión presupuestaria (siguiendo la terminología adoptada en la Ley General Presupuestaria), constituye la tercera fase del ciclo presupuestario, siendo competencia del Poder Ejecutivo ${ }^{1}$.

Podemos afirmar por tanto que la fase de ejecución de los Presupuestos afecta fundamentalmente a la gestión de los gastos públicos, es decir, a la gestión del Presupuesto de gastos. Tiene lugar así la utilización o aplicación de los créditos presupuestarios a las finalidades para las que fueron autorizados. En cambio la ejecución de los ingresos no deriva de la Ley de Presupuestos, que no los autoriza sino que simplemente los prevé; de quien deriva es de las propias leyes que establecen y regulan los diferentes tipos de ingresos presupuestarios, entre ellos los de carácter tributario. La Ley General Presupuestaria (LGP) se refiere en sus arts. 80 y 81 a la gestión del Presupuesto de ingresos y a la gestión de las devoluciones, respectivamente.

\footnotetext{
1 Recuérdese a este respecto que, con la denominada «bifurcación o desdoblamiento de la actividad financiera» (circunstancia que se inicia a raíz de la Constitución de 1869), la Ley de Presupuestos experimenta una notable transformación, al pasar de establecer una autorización respecto de los ingresos a contener una mera previsión de los mismos, teniendo lugar su establecimiento y regulación mediante otras normas de vigencia indefinida. No obstante, respecto de los gastos públicos la Ley de Presupuestos mantuvo su carácter de autorización por el Parlamento, siendo ésta indispensable para su efectiva realización. En este sentido puede consultarse la Sentencia del Tribunal Constitucional 3/2003, de 16 de enero.
} 
Y es que, a pesar de que ejecutar el Presupuesto es realizar tanto los ingresos como los gastos, la eficacia presupuestaria se proyecta de un modo especial sobre estos últimos. En cierta medida la idea de ejecución presupuestaria podría circunscribirse a la realización del gasto autorizado por la Ley de Presupuestos. Porque, desde un punto de vista jurídico, ejecutar los presupuestos no es sino hacer uso de las autorizaciones presupuestarias para realizar los gastos públicos utilizando, en definitiva, los créditos presupuestarios aprobados. Téngase presente que, respecto de los ingresos públicos, el Presupuesto se limita a recoger una mera estimación de los que se prevén obtener. Precisamente por ello la realización de los ingresos ha de acomodarse a las leyes que los regulan.

La ejecución del Presupuesto supone el empleo por parte de la Administración de aquellos créditos autorizados a gastar para el desarrollo de sus funciones. En base a dichos créditos la Administración podrá contraer nuevas obligaciones y, por otra parte, dar cumplimiento a las obligaciones derivadas de relaciones nacidas con anterioridad o sencillamente derivadas de la directa ejecución de una Ley.

En todos estos casos la existencia del crédito presupuestario es condición necesaria, ya sea para la contracción de la obligación por parte de la Administración o, en su caso, para el cumplimiento de las obligaciones preexistentes así como de las derivadas de una nueva norma presupuestaria.

Conviene precisar en todo caso que, al tratarse de la gestión de los gastos públicos o del Presupuesto de gastos, no se atiende ni a la fuente ni al momento del nacimiento de las obligaciones de contenido económico de la Hacienda Pública (arts. 5.1 y 20 LGP), sino tan sólo al de su exigibilidad (art. 21 LGP), es decir, al momento del gasto. Así las cosas, la gestión del Presupuesto de gastos constituye el procedimiento de gestión de los créditos presupuestarios orientado a la finalidad de extinguir las obligaciones de la Hacienda Pública que resulten exigibles (arts. 21 y 22 LGP) ${ }^{2}$.

Nos hallamos pues en presencia de un verdadero procedimiento administrativo de carácter complejo integrado por un conjunto de actos concatenados en el que cada uno trae su causa del anterior, constituyendo a la vez presupuesto para el siguiente. Estos actos tienden además, de manera conjunta, hacia la consecución de un fin unitario que les da sentido, como es la realización efectiva de un gasto público.

\footnotetext{
2 Afirma a este respecto el Tribunal Constitucional en el F.J. $.^{\circ} .^{\circ}$ de su Sentencia 13/1992, de 6 de febrero, que «Los créditos consignados en los estados de gastos de los Presupuestos Generales del Estado no son fuente alguna de obligaciones; sólo constituyen autorizaciones administrativas para que dentro de unos determinados límites la Administración del Estado pueda disponer de los fondos públicos necesarios para hacer frente a sus obligaciones. La fuente de éstas debe buscarse fuera de dichas consignaciones presupuestarias, ya sean en la Ley, ya en los negocios jurídicos o en los actos o hechos que según Derecho las generen (...) Por tanto como se reiteró en la STC 146/1986, F.J. ${ }^{\circ}$ 8. $^{\circ}$, las Leyes de Presupuestos Generales del Estado (...) sólo autorizan la disposición de los fondos y predeterminan el concepto por el que autorizan su uso (...)».
} 
Por otra parte, el hecho de que dentro de este procedimiento coexistan actos de muy diversa índole (internos y externos, preparatorios, de trámite y resolutorios) no perjudica su calificación como procedimiento administrativo. Y tampoco afecta a dicha calificación la circunstancia de que algunos de estos actos resulten ser, a su vez, consecuencia o acto resolutorio de otro procedimiento ${ }^{3}$. Piénsese que el desarrollo de este procedimiento, así como su culminación, vienen impuestos a la Administración como modo de satisfacer y de cumplir la preexistente obligación económica, jurídicamente vinculante. Nos hallamos en suma ante una actuación debida que permite configurar una función de gasto público en sentido estricto.

Pues bien, es en el Capítulo III del Título X de la Ley 57/2003, que vino a modificar los arts. 133 a 136 de la Ley Reguladora de las Bases del Régimen Local (LBRL), donde queda regulada la organización de la gestión económicafinanciera de los Municipios de acuerdo con un conjunto de criterios y de principios. Así, en primer lugar cabe referirse al cumplimiento del objetivo de estabilidad presupuestaria. Y, en segundo término, a la separación de las funciones de contabilidad y fiscalización.

Ciertamente tiende a otorgarse una gran importancia a uno de los documentos que integran los Presupuestos Generales de la Entidad Local como es el relativo a las Bases de Ejecución Presupuestaria, que constituye uno de los instrumentos fundamentales para ejercer la autonomía y capacidad de autorregulación de las Entidades Locales, objetivo fundamental de toda la normativa presupuestaria. A este respecto podría decirse que, por su alcance y contenido, las Bases de Ejecución del Presupuesto se configuran como una auténtica Ley Anual de Presupuestos para la Corporación Local. Piénsese además que es al hilo de la ejecución del presupuesto de gastos donde se fija un esquema integrado por diversas fases de obligado cumplimiento en la Administración Central, a saber: autorización de gasto, disposición o compromiso de gasto, reconocimiento o liquidación de la obligación y ordenación del pago.

Las Entidades Locales, a la terminación del ejercicio presupuestario, han de formar la Cuenta General que ponga de manifiesto la gestión realizada en los aspectos económico, financiero, patrimonial y presupuestario, estando constituida tanto por documentos presupuestarios como por los propios de la contabilidad por partida doble.

Tiene lugar así una separación radical entre el presupuesto corriente (presupuesto del ejercicio en curso) y la agrupación de presupuestos cerrados (integrado por las obligaciones de pago y derechos de cobro procedentes de ejercicios anteriores). Estos derechos y obligaciones pendientes de cobro y pago, respectivamente, se controlan de forma independiente respecto a los correspondientes al ejercicio corriente. Y, a pesar de que cada uno de los presupuestos que

3 Esto es lo que sucede, por ejemplo, con los actos de intervención. 
se integran en el general recogen gastos e ingresos de naturaleza presupuestaria, este hecho no impide que a lo largo del ejercicio puedan generarse en el seno de un determinado Ente Público gastos e ingresos económicos de naturaleza no presupuestaria, lo que conlleva que sea fundamental diferenciar entre gastos e ingresos como figuras presupuestarias y gastos e ingresos como flujos económicos.

\section{LA GESTIÓN DE LOS GASTOS PÚBLICOS}

\section{Introducción}

El procedimiento administrativo de gasto público es objeto de regulación en los arts. 73 a 79 de la LGP, así como en la Orden Ministerial de 6 de mayo de 1994, por la que se aprobó el Plan General de Contabilidad Pública, y en otras tres Órdenes Ministeriales, encargadas de aprobar: la Instrucción de Contabilidad para la Administración General del Estado (Orden Ministerial de 23 de mayo de 2002, modificada por la Orden Ministerial de 26 de enero de 2004); la Instrucción de Operatoria Contable a seguir en la ejecución de gasto del Estado (Orden Ministerial de 1 de febrero de 1996, modificada por la Orden Ministerial de 23 de mayo de 2002 y por la Orden Ministerial de 26 de enero de 2004) y los documentos contables que han de ser utilizados por la Administración General del Estado (Orden Ministerial de 1 de febrero de 1996, modificada igualmente por las ya citadas Órdenes de 23 de mayo de 2002 y de 26 de enero de 2004) ${ }^{4}$.

Constituye un hecho innegable que el procedimiento administrativo de gasto público a seguir no es siempre el mismo, debiendo diferenciarse entre un procedimiento ordinario o tipo y los procedimientos especiales, que integran los denominados anticipos de caja fija, los pagos a justificar y la tramitación anticipada de los expedientes de gasto.

Señala el art. 30 del Real Decreto 500/1990, de 20 de abril, por el que se desarrolló el Capítulo Primero del Título Sexto de la antigua Ley 39/1988, de

\footnotetext{
4 Véanse a este respecto, con carácter general, BAYONA DE PEROGORdo, J J., «Gasto Público», Derecho Financiero y Tributario, EJB, Vol. II, Civitas, Madrid, 1994, págs. 1823 y ss., SÁEZ DE ORMIJANA, F. A. y Bravo GutiérRez, F. J., «El proceso administrativo en la ejecución del gasto público», Hacienda Pública Española, núm. 19, 1972, págs. 51 y ss., VICENTE-ARCHE DOMINGO, F., «El gasto público y su sostenimiento en la Hacienda Pública», Revista Española de Derecho Financiero, núm. 3, 1974, págs. 25 y ss., GARCíA ORTEGA, J. A., «El cierre del ejercicio presupuestario», en la obra colectiva Análisis de la Ley General Presupuestaria, Instituto de Estudios Fiscales, 1977, págs. 174 y ss., GONZÁLEZ SÁNCHEZ, M., «La relación jurídica del gasto público», Presupuesto y Gasto Público, núm. 1, 1979, págs. 37 y ss., PASCUAL GARCÍA, J., El procedimiento de ejecución del gasto público, Instituto Nacional de Administración Pública, Madrid, 1986, págs. 134 y ss., INTERVENCIÓN GENERAL DE LA ADMINISTRACIÓN DEL ESTADO (IGAE), «Obligaciones y gastos», Documento número 3, Madrid, 1992, págs. 63 y ss., LuCAS RUIZ, E., Manual para la confección, ejecución y contabilización de los presupuestos de las Entidades Locales, Bayer Hermanos, 1994, pág. 153 y García Novoa, C., «Ciclo presupuestario. La ejecución del Presupuesto», en la obra colectiva Manual de Derecho Presupuestario, Comares, Granada, 2001, págs. 134 y ss.
} 
28 de diciembre, reguladora de las Haciendas Locales, en materia de presupuestos, y a través del cual se promulgó el denominado Reglamento Presupuestario de las Corporaciones Locales ${ }^{5}$, así como diversas disposiciones de menor rango destinadas a la regulación de cuestiones de carácter más concreto, que los créditos consignados en el presupuesto de gastos podrán encontrarse en cualesquiera de las situaciones siguientes: créditos disponibles, que son los consignados inicialmente en el presupuesto o resultado de operaciones de modificación presupuestaria; créditos retenidos pendientes de utilización, que constituyen aquellos que se reservan para la autorización de gastos o para la transferencia de crédito, por una cuantía determinada; y créditos no disponibles, que comprenden aquellos que el Pleno de la Corporación ha dispuesto que no se puedan utilizar para otra finalidad que la prevista.

Pues bien, a la hora de analizar el procedimiento ordinario de ejecución (o gestión) de los gastos presupuestarios, y partiendo de la existencia de crédito disponible (en el nivel de vinculación jurídica del gasto), la gestión del gasto se realiza según las siguientes fases (art. 52 del Real Decreto 500/1990): aprobación del gasto, compromiso de gasto, reconocimiento de la obligación, ordenación del pago y pago material. No obstante, resulta posible sintetizar las citadas fases del procedimiento administrativo del gasto público en dos fases de carácter esencial. En primer lugar, la ordenación del gasto, que supone la afectación a un destino concreto de los créditos presupuestados y que culmina con la denominada contracción, liquidación o reconocimiento de la obligación. Y, en segundo término, la ordenación del pago, de carácter ejecutivo y orientada hacia el cumplimiento y efectividad de la obligación de pago reconocida. Ambas fases, de carácter esencial, podrán darse conjuntamente y en unidad de actuación administrativa para la ejecución de un determinado gasto. Ahora bien, ha de quedar claro que tienen un carácter sustancialmente distinto, quedando integradas por actos diferentes ${ }^{6}$.

Una vez cumplidas las formalidades derivadas de la aprobación del Presupuesto de los Entes Locales, se inicia así lo que la doctrina denomina sus fases de ejecución que, en lo referente a los gastos, comprende las etapas de: autorización; disposición; reconocimiento; y pago. Ahora bien, para poder efectuar cualquier gasto resulta necesario conocer inicialmente en qué estado se encuentran los créditos consignados en el Presupuesto, que pueden ser de las siguientes clases.

En primer lugar, créditos disponibles, esto es, los aprobados con el Presupuesto del Ente Local o los que proceden de la concesión de créditos extraordi-

\footnotetext{
5 Este Real Decreto 500/1990, de 20 de abril, desarrolló los preceptos de la Ley de 1988 en relación a esta materia. Se trata de una norma que, si bien no fue adaptada al Real Decreto Legislativo 2/2004, de 5 de marzo, por el que se aprueba el Texto Refundido de la Ley Reguladora de las Haciendas Locales, puede ser utilizada respecto a los artículos de la ley no modificados.

6 En todo caso las actuaciones a desarrollar para autorizar la realización de un gasto quedan reflejadas en un expediente de gasto, pudiendo resultar acumuladas en un solo acto las fases de ejecución precisas cuando la naturaleza de la operación o del gasto así lo determinen (art. 73.6 LGP).
} 
narios, suplementos de créditos o cualquier otra modificación de las previstas al efecto, no habiéndose realizado sobre ellos ninguna retención o declaración de no disponibilidad.

En segundo término, los créditos retenidos pendientes de utilización, procediéndose a reservar la totalidad o parte de un crédito presupuestario para destinarlo a una finalidad concreta, bien para efectuar un gasto o para transferir su importe a otro crédito presupuestario. Y, por último, los llamados créditos no disponibles. Téngase presente que puede llegar a plantearse la necesidad de bloquear la totalidad o parte de un crédito asignado a una partida presupuestaria, correspondiendo al Pleno de la Corporación adoptar esta medida. Ello determina la imposibilidad de poder utilizar dicho crédito para cualquier finalidad.

La ejecución del Presupuesto de los Entes Locales se encuentra regulada en los arts. 184 y siguientes del TRLHL, atribuyéndose al Presidente de la Entidad Local la autorización, disposición, reconocimiento de obligaciones y ordenación de pagos que deban realizarse al efecto. Esta última, la ordenación de pagos, ha de efectuarse de acuerdo con el Plan de Disposición de Fondos de la Entidad, previsto en el art. 187 del citado Texto Refundido.

\section{Fases de ejecución de los presupuestos locales}

\section{A) Autorización del gasto}

Analicemos detenidamente las distintas fases de ejecución existentes en el marco de los Presupuestos de los Entes Locales ${ }^{7}$. La primera de ellas, como ya sabemos, es la relativa a la autorización del gasto (fase A). Este proceso comienza con la propuesta y ordenación de gastos, a través de la cual se solicita la realización de un gasto, debiendo detallarse sus características y concretarse su importe aproximado. Y ello en aras de que se produzca la fiscalización previa por parte del Interventor Local, destinada a acreditar la existencia de crédito suficiente ${ }^{8}$. Se trata de un trámite que lleva aparejada, además, la retención del crédito por la cantidad estimada del gasto.

\footnotetext{
7 Acerca de la gestión del Presupuesto de los Entes Locales véanse, entre otros, los trabajos de ARNAU BerniA, V., «La gestión presupuestaria de las Entidades Locales», Presupuesto y Gasto Público, núm. 8, 1992, págs. 156 y ss., SÁNCHEZ REVENGA, J., «La reforma presupuestaria de las Haciendas Locales: incidencia en sus sistemas de gestión», Presupuesto y Gasto Público, núm. 8, 1992, págs. 76 y ss., HerRERo IGLESIAS, A., «El presupuesto de los Entes Locales como instrumento de su gestión», Actualidad Financiera, núm.18, 1994, págs. 53 y ss. y, más recientemente, VALENZUELA VILLARUBIA, I., El régimen Presupuestario de los Entes Locales. El Presupuesto como instrumento de gestión y planificación, Thomson-Aranzadi, Pamplona, 2007, págs. 168 y ss.

8 A esta labor de fiscalización se refieren CERVERA NOTARI, M., «La Auditoría de las Entidades Locales», Revista de Hacienda Local, núm. 90, 2000, págs. 261 y ss. y MATA REMOLINS, L., «La función interventora en la Administración Local en la modalidad de control previo limitado de los gastos», Revista de Hacienda Local, núm. 90, 2000, págs. 171 y ss.
} 
Ya en esta primera etapa del procedimiento de ejecución del gasto tiene lugar el reconocimiento contable de las obligaciones para la Hacienda Local y, en consecuencia, el nacimiento de la obligación de pago, en tanto en cuanto se compromete la totalidad o parte de un crédito presupuestario para su satisfacción. Como es lógico, dicha actuación culminará con la liquidación de la obligación, en la que resulta determinado su importe exacto y su exigibilidad, originándose así la afectación definitiva del crédito por dicho importe y su destino a esa concreta finalidad.

El desarrollo de esta primera fase relativa a la ordenación del gasto se caracteriza, además, por la existencia de una serie de actos, unos internos y otros externos, conducentes a lograr la cuantificación y la vinculación de la consignación presupuestaria, la cual se presenta como un requisito previo imprescindible para que pueda ponerse en marcha el procedimiento, pero sin que ello suponga que se inserte en el mismo.

La autorización del gasto representa el acto mediante el cual se acuerda la realización de un acto por una cuantía cierta o aproximada, reservándose a tal fin la totalidad o parte del crédito presupuestario, estableciéndose la competencia para autorizar gastos en las Bases de Ejecución y siendo respetadas las competencias establecidas en la LRBRL para los distintos órganos de Gobierno Local.

En efecto, a través de dicho acto se autoriza la realización de un gasto determinado por una cuantía cierta o aproximada, reservándose a tal fin la totalidad o parte de un crédito presupuestario. Dicha autorización determina propiamente el inicio del procedimiento de ejecución del gasto, si bien no implica relaciones con terceros externos a la Corporación Local (caso, por ejemplo, de la Hacienda Pública o de la Seguridad Social.

Existen no obstante una serie de actuaciones o trámites de carácter previo reflejados en el expediente de gasto y que preceden a esta aprobación o autorización. Así, cabe aludir en primer lugar a la propuesta de gasto o financiera, que representa el acto administrativo en virtud del cual se inicia la tramitación financiera de la ejecución del presupuesto de gastos. Esta propuesta de gasto o financiera se caracteriza por recoger en una exposición de motivos la necesidad de llevar a cabo la operación así como la plasmación económica de las características del gasto que va a ejecutarse. Suele presentar como antecedente una propuesta técnica, si bien cabe igualmente la posibilidad, en el supuesto de que esta no se considere necesaria debido a la naturaleza o menor importancia del gasto, de que en la propia propuesta se hagan constar las características técnicas de la necesidad a satisfacer ${ }^{9}$.

\footnotetext{
9 Con carácter general estas propuestas son formuladas por los Servicios dependientes del Ordenador del Gasto. Y, a pesar de que no responden a un modelo normalizado, han de contener como menciones mínimas el importe del gasto, la imputación presupuestaria, la necesidad a satisfacer y las disposiciones legales que lo amparan.
} 
Como segundo trámite de carácter previo hemos de referirnos al certificado de existencia y retención de crédito. La necesidad de su aportación reside en el deber que pesa sobre el ordenador del gasto de no autorizar gastos por encima de los créditos concedidos, circunstancia ésta que se acredita mediante el citado certificado, expedido por los servicios de contabilidad a través de un Documento «RC». Asimismo ha de tener lugar una fiscalización previa del gasto por la Intervención Local, cuando proceda. Y debe tenerse presente que las particulares leyes que regulan las distintas clases de gasto pueden establecer requisitos o trámites adicionales que habrá que examinar en cada caso.

Pues bien, una vez aprobado el expediente de gasto tiene lugar la formulación del Documento Contable «A» por la parte correspondiente al presupuesto en curso. Este Documento ha de servir como soporte y justificante de la operación, de manera que cuando se contrate por parte de Ente Local una obra, adquisición o servicio en un importe inferior al valor por el que se hubiera efectuado la autorización se producirá una baja por la diferencia, la cual habría de tramitarse mediante otro documento análogo al que originó la autorización, pero de carácter inverso en este caso, el documento «A/». El reflejo contable de este segundo documento es idéntico al realizado en ésta por importe negativo ${ }^{10}$.

Tal y como se ha precisado con anterioridad, es competencia del Presidente de la Corporación la autorización de aquellos gastos que tengan una duración no superior a un año o que no exijan créditos superiores a los consignados en el Presupuesto anual, pudiendo no obstante ser delegadas estas atribuciones tanto en la Comisión de Gobierno como en los Concejales Delegados. En todo caso compete al Pleno de la Corporación la autorización de gastos que excedan de los límites anteriormente citados.

\section{B) Disposición o compromiso del gasto}

La disposición o compromiso del gasto (fase $\mathrm{D}$ ) representa el acto mediante el cual se acuerda, tras el cumplimiento de los trámites legalmente establecidos, la realización del gasto previamente autorizado por un importe exactamente determinado.

Sin lugar a dudas es éste un acto con relevancia jurídica para con terceros, en tanto en cuanto vincula a la Corporación Local a la realización de un gasto concreto y determinado. Y es que a través de esta segunda gran fase se acuerda, una vez cumplidos los trámites previstos al efecto, la realización de gastos previamente aprobados por un importe determinado o determinable ${ }^{11}$.

\footnotetext{
10 De la misma manera se procedería en el supuesto de que se decidiera anular el expediente de gasto por cualquier otra causa.

11 Véase a este respecto lo dispuesto en el art. 73.3 de la LGP.
} 
Podemos afirmar en consecuencia que la disposición o el compromiso del gasto representa el acto más significativo de todo el procedimiento de ejecución presupuestaria de los Entes Locales, dada la relevancia jurídica que adquiere para con los terceros, ya que mediante él resulta vinculada la Hacienda Local o la Seguridad Social a la realización del gasto a que se refiera en la cuantía y condiciones establecidas.

De este modo el gasto deja de ser algo puramente interno y pasa a convertirse en un compromiso con un tercero que, en principio, la Administración Local habrá de cumplir, una vez que el tercero haya procedido a satisfacer debidamente la prestación a su cargo de conformidad con las exigencias de la regla del «servicio hecho» a que se refiere el art. 21.2 de la LGP ${ }^{12}$. Ciertamente en determinados supuestos el compromiso de gasto podrá darse en unidad de acto con la anterior autorización. Ahora bien, debe quedar claro que nos encontramos ante dos operaciones diferenciadas.

El compromiso existente entre la Administración Local y el tercero ha de realizarse conforme a unos procedimientos inspirados en criterios de publicidad, concurrencia e imparcialidad de las decisiones. Estos procedimientos se encuentran tasados y vienen establecidos por las normas específicas reguladoras de cada tipo de gastos. Los más significativos, tanto por la frecuencia con la que se desarrollan como por el volumen de recursos presupuestarios que se compromete a través de ellos, son los procedimientos de contratación y los de subcontratación, regulados respectivamente en la legislación de contratos de los Entes públicos y en la legislación sobre subvenciones. En definitiva, ha de estarse a las reglas de contratación (pliego de condiciones, licitación pública o adjudicación directa, etc.).

Por otra parte, la relevancia externa que adquiere la disposición del gasto y la vinculación jurídica que determina para la Administración justifican que su adopción se realice siguiendo un conjunto de reglas precisas, debiendo respetarse tanto aquellas de carácter sustantivo reguladoras de las materias de que se trate como, sobre todo, las de carácter presupuestario ${ }^{13}$. Es precisamente por ello por lo que este acto ha de ser objeto de fiscalización previa a cargo de la Intervención Local como mecanismo de control que permite asegurar que la Administración no se compromete más allá de lo que ha sido autorizada por los Presupuestos.

\footnotetext{
12 Establece concretamente este art. 21.2 de la Ley 47/2003 que «Si las obligaciones de la Hacienda Pública tienen por causa prestaciones de servicios, el pago no podrá efectuarse si el acreedor no ha cumplido o garantizado su correlativa obligación».

13 Dentro de estas últimas destaca la contenida en el art. 11 del RDLeg. 2/2007, de 28 de diciembre, por el que se aprueba el Texto Refundido de la Ley General de Estabilidad Presupuestaria. Dicho precepto exige que los compromisos de gasto contenidos en cada política presupuestaria se detallen para cada año en los Escenarios Presupuestarios Plurianuales, al disponer que «Con carácter previo al proceso de elaboración de los Presupuestos Generales del Estado, el Ministerio de Economía y Hacienda confeccionará unos escenarios de previsión plurianual referidos a ingresos y gastos en los términos previstos en la Ley 47/2003, de 26 de noviembre, General Presupuestaria».
} 
De cualquier manera este compromiso o disposición del gasto ha de materializarse en el documento contable «D». Por su parte, la anulación de compromisos de gastos se producirá mediante documentos análogos de carácter inverso $(\ll \mathrm{D} / »)$, siendo el asiento a que dé lugar semejante al provocado por el compromiso pero de signo negativo, lógicamente.

Aquella reserva de crédito que se hubiese producido con motivo de la autorización anteriormente indicada y que tuviese un carácter meramente provisional se convierte ahora, por medio de la disposición del gasto, en una definitiva reserva por el importe exacto. Tiene lugar así una afectación del crédito presupuestario al fin para el que se compromete, rebajándose el montante del crédito disponible para nuevas autorizaciones. ¿Y qué órganos son competentes para aprobar la disposición del gasto? Con carácter general el Presidente y el Pleno de la Corporación, si bien la ley permite igualmente la delegación en la Comisión de Gobierno o en los Concejales Delegados.

\section{C) Reconocimiento de la obligación}

A la hora de analizar la fase relativa al reconocimiento de la obligación (fase $\mathrm{O}$ ), conviene volver a recordar que en la fase anteriormente estudiada ha nacido una relación contractual, si bien aún no existe la obligación de pagar, puesto que no se ha hecho entrega de los bienes o servicios. Ahora bien, en esta fase los referidos hechos ya han acaecido, por lo que se debe reconocer la obligación.

Define la obligación de pago el Documento Núm. 3 «Obligaciones y gastos» de la Comisión de Principios y Normas Contables Públicas (CPNCP) de la Intervención General de la Administración del Estado (IGAE) ${ }^{14}$ como «Aquella deuda actual, cierta o estimada, que supone un pasivo para la parte deudora, proveniente de transacciones, acuerdos o acontecimientos de naturaleza presupuestaria o no presupuestaria acaecidos en tiempo pasado, en virtud de la cual la entidad se ha comprometido a realizar, al vencimiento de la misma, una prestación evaluada económicamente».

Nos hallamos en presencia de un concepto que engloba tanto obligaciones de naturaleza presupuestaria como no presupuestaria. En efecto, se trata de obligaciones que nacen de la ley, de los negocios jurídicos y de los actos que, según Derecho, las generen, siendo necesario al efecto diferenciar entre una

\footnotetext{
14 Esta Comisión fue creada mediante Resolución de la Secretaría de Estado de Hacienda de 28 de diciembre de 1990, constituyéndose como un grupo de trabajo integrado por profesionales de las distintas Administraciones Públicas (estatal, autonómica y local), del campo universitario y de otras corporaciones e instituciones profesionales públicas y privadas, cuyos resultados se materializan en un conjunto de documentos que recogen criterios generales de contabilización, una vez estudiada la aplicación de todos y cada uno de los principios contables públicos a las rúbricas más significativas de la contabilidad, como es el caso de los gastos con financiación afectada.
} 
obligación y un encargo futuro ya que, en este último, la decisión de adquirir bienes o incurrir en gastos en el futuro no conlleva el nacimiento de una obligación de pago.

El reconocimiento de una obligación representa así el proceso por el cual se incorpora al balance un elemento que cumple con las características de la definición de obligación de pago. A este respecto será requisito necesario el cumplimiento por parte del acreedor de la prestación a su cargo (regla de servicio hecho), a excepción de los supuestos de obligaciones recíprocas de la Entidad (caso, por ejemplo, de la concesión de una subvención a cargo de aquélla), en los que es requisito previo al reconocimiento el nacimiento del derecho del acreedor en virtud de la ley o de un acto administrativo que lo otorgue ${ }^{15}$.

Existen sin embargo excepciones a esta regla general de «servicio hecho», pudiéndose reconocer obligaciones con anterioridad al cumplimiento de la prestación a cargo del acreedor. Así sucede cuando existen procedimientos administrativos legalmente establecidos que disponen la realización del pago sin la previa aportación de la documentación acreditativa (por ejemplo, los pagos a justificar), así como cuando en el contrato entre las partes se contempla el sistema de «abonos a cuenta» por operaciones preparatorias realizadas por el contratista o en los contratos que, hallándose regidos fundamentalmente por la normativa privada, incorporan cláusulas de pagos previos a la prestación convenida.

Como norma general las obligaciones se registran en el momento en el que se dicten los correspondientes actos de reconocimiento y liquidación, si bien existen excepciones a este principio general. De hecho, a fecha de cierre del período deben registrarse aquellas obligaciones que, no habiéndose dictado aún el correspondiente acto formal administrativo de reconocimiento y liquidación, se deriven de bienes y servicios efectivamente recibidos por la Entidad. Y análogo tratamiento adquieren los intereses devengados y no vencidos como consecuencia de pasivos financieros.

Igualmente pueden reconocerse obligaciones cuya evaluación se realice mediante métodos estimativos. Estas obligaciones son no presupuestarias y su registro se efectúa a fin de ejercicio en los supuestos de estimación anual, o bien en el momento del nacimiento de la responsabilidad que vayan a cubrir.

Proyectando estas consideraciones sobre el ámbito objeto de nuestro estudio podemos afirmar que el reconocimiento de la obligación constituye el acto administrativo mediante el cual se declara la existencia de un crédito exigible contra la Hacienda Pública Local derivado de un gasto aprobado y comprome-

\footnotetext{
15 Ya se trate de obligaciones provenientes o no de la ejecución del Presupuesto, su cuantificación habrá de producirse por su «valor de reembolso», definiéndose el mismo como la cantidad a pagar en el momento de su vencimiento, integrada por el principal de la deuda más, en su caso, los rendimientos implícitos que pudieran haberse pactado en la financiación de la operación.
} 
tido, como consecuencia de la realización de la prestación, y que comporta la propuesta de pago correspondiente ${ }^{16}$.

El reconocimiento de la obligación representa así el acto mediante el cual se declara la existencia de un crédito exigible contra la Entidad Local derivado de un gasto autorizado y comprometido. En otras palabras, se reconoce la obligación de pagar como consecuencia de la realización de las obras, prestación de servicios, o adquisición de materiales que se contrataron con otras personas. Como es lógico, con carácter previo al reconocimiento de la obligación habrá de acreditarse documentalmente ante el órgano competente (el Presidente de la Corporación), de acuerdo con lo dispuesto al efecto.

Obsérvese por tanto que, en aquellos casos en los que el gasto no subsigue a una concreta contraprestación, dicho acto se subsume en los restantes que integran el procedimiento, habida cuenta de que no resulta posible la verificación que normalmente le antecede. Así sucede, por ejemplo, con las subvenciones abonadas a Entes públicos o privados para la realización de ciertas actividades, y más aún tratándose de aquellas subvenciones concedidas sin afectación a una concreta finalidad.

Dentro del procedimiento administrativo de gasto el reconocimiento de la obligación representa, sin lugar a dudas, la fase definitoria del mismo, ya que es a partir de ese preciso instante cuando puede afirmarse que el crédito ha sido ejecutado desde el punto de vista presupuestario, a pesar de que todavía no se haya procedido a su pago.

El acto de reconocimiento de la obligación se materializa en el Documento Contable «O».Y, al igual que sucede con los anteriores documentos a los que nos hemos referido, existen documentos «O/» inversos destinados a contabilizar las anulaciones correspondientes.

La competencia para su adopción resulta atribuida al mismo órgano que hubiese dictado los otros actos. En caso contrario, como regla general, la contracción de la obligación suele ir precedida de las certificaciones de obra, liquidaciones de cuentas y, en definitiva, de todos los justificantes acreditativos del «servicio hecho». Así las cosas, corresponde al Presidente de la Corporación el reconocimiento y liquidación de las obligaciones derivadas de compromisos de gastos legalmente adquiridos. Ahora bien, tratándose de obligaciones derivadas del reconocimiento extrajudicial de créditos dicha competencia recae en el Pleno de la Corporación.

16 Tal y como se encarga de precisar el art. 73.4 de la LGP, refiriéndose al marco presupuestario estatal, «El reconocimiento de obligaciones con cargo a la Hacienda Pública estatal se producirá previa acreditación documental ante el órgano competente de la realización de la prestación o el derecho del acreedor, de conformidad con los acuerdos que en su día aprobaron y comprometieron el gasto. El Ministro de Economía y Hacienda, previo informe de la Intervención General de la Administración del Estado, determinará los documentos y requisitos que, conforme a cada tipo de gastos, justifiquen el reconocimiento de la obligación». 
Todo reconocimiento de una obligación lleva siempre implícita la correspondiente propuesta de pago, que constituye aquella solicitud efectuada por la autoridad competente que ha reconocido la existencia de una obligación para que, de acuerdo con la normativa vigente, se proceda a efectuar la ordenación de su pago. Representa por tanto la propuesta de pago el último acto del proceso de ordenación del gasto a través del cual el representante del centro gestor que ha reconocido la existencia de una obligación a pagar a favor de un interesado solicita, dada su condición de ordenador de pagos que, de acuerdo con la normativa vigente, orden su pago. Esta propuesta de pago se materializa en un Documento Contable $\ll \mathrm{K} » 17$.

¿Cabría la posibilidad de que, en aquellos casos en los que la naturaleza de la operación o gasto así lo determine, se acumulen en un solo acto las fases de ejecución precisas al efecto? La respuesta a la citada cuestión ha de ser afirmativa. La acumulación de actos es posible. De hecho, en la mayoría de supuestos resulta consustancial al tipo de gasto que se realiza, adquiriendo en otros un carácter simplemente conveniente por razones de eficiencia o de economía procesal $^{18}$.

En efecto, suele ser normal en numerosas actuaciones de gestión presupuestaria que se cumplimenten dos o más actos de la ordenación del gasto de forma simultánea, originándose así un acto administrativo de contenido plural por el que se aprueba un gasto a la vez que se compromete, reconociéndose la obligación y proponiéndose su pago. Esto es lo que sucede, por ejemplo, en los gastos de personal o en las subvenciones con asignación nominativa.

De cara a llevar a cabo la ordenación de todos estos gastos que admitan la acumulación de actos han de expedirse documentos contables mixtos o múltiples, los cuales sirven de soporte para la toma de razón mediante una única operación contable, también denominada múltiple, de la totalidad de actos que hayan sido objeto de acumulación. No obstante debe quedar claro que la acumulación en un único acto administrativo de dos o más fases de ejecución de gastos presupuestarios produce los mismos efectos que si dichas fases resultasen acordadas en actos administrativos separados. Así, por ejemplo, acordándose la autorización y el compromiso de gasto en un único acto se expide un Documento mixto «AD». Y si en un mismo acto se hubiesen acumulado la autorización del gasto, su compromiso y el reconocimiento de la obligación, se expediría un Documento mixto $« \mathrm{ADOK}{ }^{19}{ }^{9}$.

17 Cabe precisar no obstante que, si bien esta actividad de proponer el pago tiene sentido en el ámbito de la Administración del Estado, donde la competencia para ordenar pagos resulta atribuida a órganos distintos de aquellos que gestionan el gasto y reconocen la obligación, no sucede lo mismo en el ámbito de los Organismos Autónomos, donde el Presidente del Organismo es, al mismo tiempo, gestor de gastos y ordenador de pagos.

18 Así lo tiene declarado, además, el art. 73.6 de la LGP.

19 En efecto, las anteriores fases de ordenación del gasto pueden acumularse en un solo acto administrativo: Documento AD (autorización-disposición); y documento ADO (autorización-disposición y reconocimiento 


\section{D) Ordenación y ejecución del pago}

Finalmente hemos de referirnos a la ordenación y ejecución del pago, que se presenta como la última gran etapa del procedimiento de ejecución del gasto público, en la que se procede a la ejecución de las obligaciones contraídas en la fase anterior, esto es, a la realización de los pagos correspondientes a las obligaciones reconocidas.

Dos son los actos que resultan comprendidos en esta última gran fase: la ordenación del pago (con la expedición del oportuno mandamiento) y el pago mismo. La ordenación de pago (fase P) representa el acto a través del cual el Ordenador de Pagos, en base a una obligación reconocida y liquidada, expide la correspondiente orden, mandamiento o libramiento de pago a favor del acreedor que figura en la correspondiente propuesta de pago y contra la Tesorería del Ente Local. Constituye pues esta orden o mandamiento un documento expedido por el Ordenador de Pagos y dirigido a la Tesorería del Ente Local para que haga efectiva la obligación económica contraída.

Según se expidan estas órdenes de pago antes o después de haber aportado ante el órgano competente la acreditación documental de la prestación o servicio a que se refieran podrán ser «en firme» 0 «a justificar». Mientras las primeras resultan expedidas una vez acreditado documentalmente el «servicio hecho» las segundas, esto es, los libramientos «a justificar», son expedidos cuando, excepcionalmente, no resulta posible aportar la documentación justificativa de los servicios y prestaciones a que se refieran antes de tramitar la propuesta de pago. De este modo adquieren el carácter de «a justificar» aquellas órdenes de pago cuyos documentos justificativos no pueden ser acompañados en el momento de su expedición, siendo expedidos en base a resolución de la autoridad competente para autorizar el gasto a que se refieran y aplicándose a los correspondientes créditos presupuestarios.

En cuanto a los llamados anticipos de caja, constituyen provisiones de fondos de carácter no presupuestario y permanente realizadas para atenciones corrientes de carácter periódico o repetitivo tales como dietas, gastos de locomoción, material de oficina no inventariable, conservación y otros similares (art. 73 del Real Decreto 500/1990). Se trata de unos fondos de la Tesorería Local que provisionalmente salen de Caja sin aplicación presupuestaria. Dichas previsiones se realizan en base a una resolución dictada por la autoridad competente para autorizar los pagos, aplicándose inicialmente al concepto no presupuestario que, a tal efecto, se determine.

Tienen la consideración de «gastos de carácter plurianual» aquellos que extienden sus efectos económicos a ejercicios posteriores a aquel en que se auto-

\footnotetext{
de la obligación). En cambio nunca podrán acumularse en un mismo acto las cuatro fases de ejecución del gasto, ya que la expedición de órdenes de pago debe ajustarse al plan de disposición de fondos establecido, tal y como señala el art. 65 del Real Decreto 500/1990, de 20 de abril.
} 
rizan y comprometen, pudiendo adquirirse compromisos de gastos de carácter plurianual siempre que su ejecución se inicie en el propio ejercicio y que, además, se encuentren en alguno de los casos siguientes: inversiones y transferencias de capital; contratos de suministros, de asistencia técnica y científica, de prestación de servicios, de ejecución de obras de mantenimiento y de arrendamiento de equipos que no puedan ser estipulados o resulten antieconómicos por un año; arrendamiento de bienes inmuebles; y cargas financieras de las deudas de la Entidad Local.

El número de ejercicios posteriores a los que pueden aplicarse los gastos referidos en los dos primeros apartados no puede ser superior a cuatro. Y, tratándose de inversiones y de transferencias de capital, el gasto que se impute a cada uno de los ejercicios futuros autorizados no puede exceder de la cuantía que resulte de aplicar al crédito inicial los siguientes porcentajes: en el ejercicio inmediato siguiente, el 70\%; en el segundo ejercicio, el 60\%; y en el tercer y cuarto ejercicio, el $50 \%$.

Dentro del ámbito de los Presupuestos de los Entes Locales esta ordenación de pagos es competencia del Alcalde, que ha de sujetarse a los créditos presupuestarios y respetar las prioridades establecidas en la vigente legislación. Por su parte el Tesorero del Ente Local no podrá efectuar pago alguno sino es mediante el oportuno mandamiento expedido por el Ordenador y previamente fiscalizado por el Interventor. Dichos pagos serán pues efectuados por la Tesorería de acuerdo con el Plan de Disposición de Fondos establecido por la Alcaldía, con base a la programación elaborada por la Tesorería y en función de las disponibilidades dinerarias y prioridades de pago legalmente establecidas $^{20}$.

Por su parte el pago representa el acto por el que la Hacienda Pública (en nuestro caso, la Hacienda Local) se libera de su deuda, quedado cancelada la respectiva obligación, que asimismo podrá extinguirse, tal y como permite el art. 22.1 LGP, «por cualquiera de las causas contempladas en el Código Civil y en el resto del ordenamiento jurídico».

\footnotetext{
20 Como seguramente se recordará, el principio de unidad de caja tuvo ya en su día reflejo en la regulación llevada a cabo por el art. 175 de la antigua LRHL de la Tesorería Local, constituida por todos los recursos financieros (dinero, valores o créditos) procedentes tanto de operaciones presupuestarias como extrapresupuestarias. En la actualidad las funciones encomendadas a la Tesorería Local pueden reducirse a las siguientes: recaudar los derechos y pagar las obligaciones; centralizar todos los fondos y valores; y responder de los avales contraídos. Para el ejercicio de tales funciones, las Entidades Locales se hallan facultadas para concertar los servicios financieros de su Tesorería con entidades de crédito y ahorro, mediante la apertura de cuentas de ingresos y pagos, cuentas restringidas de recaudación o de pagos y cuentas financieras de colocación de excedentes de Tesorería. Adicionalmente dichas entidades pueden autorizar la existencia de caja de efectivo para los fondos de las operaciones diarias. Véanse a este respecto, con carácter general, GUTIÉRREZ ROBLES, A., «Los déficits del Tesoro», Presupuesto y Gasto Público, núm. 9, 1981, págs. 123 y ss. y «La determinación del límite legal en algunas operaciones del Tesoro», Presupuesto y Gasto Público, núm. 18, 1988, págs. 453 y ss. y MARRón GómEZ, A., «El Tesoro Público: sus funciones», en la obra colectiva Estudios conmemorativos de la Inspección general de la Hacienda Pública (1881-1981), Instituto de Estudios Fiscales, Madrid, 1981, págs. 67 y ss.
} 
Sin lugar a dudas, el pago representa la principal forma de extinción de las obligaciones económicas de la Hacienda Local. Ahora bien, no es la única, dado que también podrán extinguirse por cualesquiera otras causas contempladas en el Código Civil y el resto del ordenamiento jurídico, como la prescripción, la compensación, etc. De hecho, como medios de pago, el art. 110 de la LGP autoriza la utilización de cualquiera de los conocidos en el tráfico jurídico: transferencia bancaria, cheque, efectivo o cualesquiera otros medios de pago, sean o no bancarios.

En la mayoría de supuestos el pago se instrumentará mediante transferencia bancaria, a través de cheque emitido por la Tesorería del Ente Local contra la cuenta correspondiente de aquélla o contra las cuentas de situación de fondos de la Tesorería del municipio abiertas en otras entidades de crédito. La expedición de la orden de pago ha de producirse a instancia del órgano que desempeña las funciones de aprobación del gasto. Dicha solicitud debe ir precedida, además, de la correspondiente justificación documental, ante dicho órgano, de la contrapartida de la obligación cuyo pago se interesa, admitiéndose excepcionalmente la posibilidad de «pagos a justificar».

Con esta última fase relativa a la ordenación del pago y a la realización del mismo finaliza el proceso de gestión de gastos, cancelándose la deuda consecuencia de las obligaciones reconocidas con terceros.

¿Existe un plazo determinado para proceder al pago? A priori no. Ahora bien establece el art. 24 de la LGP, refiriéndose a la Hacienda Pública estatal, que si la Administración no pagara al acreedor de aquélla dentro de los tres meses siguientes al día de notificación de la resolución judicial o del reconocimiento de la obligación, habría de abonarle el interés señalado en el art. 17.2 de dicho texto legal sobre la cantidad debida. Y ello desde que el acreedor, una vez transcurrido dicho plazo, reclame por escrito el cumplimiento de la obligación. Obsérvese por tanto como el plazo para proceder al pago resulta implícitamente fijado en tres meses siguientes al día de notificación del reconocimiento de la obligación.

Como es lógico, las cantidades adeudadas a la Hacienda Local devengan interés de demora desde el día siguiente al de su vencimiento. Así sucederá, por ejemplo, con las cantidades recaudadas a través de entidades colaboradoras, cuentas restringidas, oficinas liquidadoras y demás entidades recaudadoras por cuenta de aquélla que no resulten ingresadas por dichas entidades en la Tesorería del municipio en los plazos establecidos ${ }^{21}$.

21 Como es sabido la Ley 24/1984, de 29 de junio, sobre modificación del tipo de interés legal del dinero, fijó en su art. 1 el referido interés legal en el tipo de interés básico del Banco de España el día en que se produzca el devengo de los intereses. No obstante, en virtud de la autorización que ese mismo precepto realiza a favor de la Ley de Presupuestos Generales del Estado, son las de cada ejercicio las que vienen fijando directamente el interés de demora. 
Como seguramente se recordará, en relación con la fijación del interés de demora en las obligaciones públicas, la STC 14/1986, de 31 de enero, declaró que dicha fijación afecta a la política económica y financiera, por lo que la misma debe ser única, correspondiendo en exclusiva al Estado su determinación, sea cual fuere la Administración obligada.

Pues bien, el art. 14 CE parecía exigir un tratamiento idéntico en cuanto al devengo y al tipo de interés de demora exigible cuando el deudor es el particular y cuando lo es la Hacienda Pública. Ello justificaba las dudas de constitucionalidad planteadas en relación con las diferenciaciones normativas existentes en favor de aquélla y respecto de los demás obligados al pago de una determinada cantidad líquida.

A pesar de lo anterior declaró el Tribunal Constitucional en su Sentencia 76/1990, de 26 de abril, refiriéndose el art. 58.2.b) de la antigua Ley General Tributaria de 1963, que el citado precepto no vulneraba el mandato constitucional contenido en el art. $14 \mathrm{CE}$ ya que, a su juicio, «Existen razonables elementos de diferenciación entre la situación en que se encuentra el contribuyente que incurre en mora en el cumplimiento del deber tributario y la Administración que devuelve lo indebidamente cobrado». Estimaba además el intérprete supremo de nuestra Constitución que tampoco resulta vulnerado el art. 25.1 $\mathrm{CE}$, en tanto en cuanto «Los intereses de demora no tienen naturaleza sancionadora, sino exclusivamente compensatoria o reparadora del perjuicio causado por el retraso en el pago de la deuda tributaria».

También el art. 45 del antiguo Texto Refundido de la Ley General Presupuestaria (actual art. 24 de la Ley 47/2003) planteaba diversos problemas de constitucionalidad. Tal y como se encargó de precisar GARCÍA TORRES ${ }^{22}$, dos eran las situaciones susceptibles de llegar a plantearse. De una parte, aquellas en los que se condena a la Hacienda Pública al pago de una cantidad líquida por resolución judicial notificada. Y, de otra, aquellas en los que la obligación económica de la Hacienda Pública, esto es, el pago de una cantidad líquida, ha sido reconocida en vía administrativa conforme al normal procedimiento de gasto. Pues bien, sólo el primer grupo de supuestos resulta relevante para los intereses procesales. En cambio, en el segundo grupo los intereses previstos en el art. 24 en relación con el art. 17.2 de la LGP, serán estrictamente moratorios ${ }^{23}$.

Estos problemas de constitucionalidad que planteaba el régimen legal de los intereses procesales exigibles a la Hacienda Pública fueron igualmente abordados en las Sentencias del Tribunal Constitucional 206/1993, de 22 de junio y

\footnotetext{
22 GARCÍA TORRES, «El art. 45 de la Ley General Presupuestaria como regla para los intereses procesales a cargo de la Hacienda Pública», La Ley, núm. 3.201, 1993, pág. 23.

23 Recuérdese que, de conformidad con lo dispuesto por este último precepto, «El interés de demora resultará de la aplicación, para cada año o período de los que integren el período de cálculo, del interés legal fijado en la Ley de Presupuestos para dichos ejercicios».
} 
69/1996, de 18 de abril. En la primera de ellas se examinaba, desde la perspectiva que proporciona el principio de igualdad previsto en el art. $14 \mathrm{CE}$, la posible inconstitucionalidad de uno de los privilegios de los que disfruta la Hacienda Pública deudora: el distinto y menor tipo de interés aplicable a los intereses procesales que corren a cargo de aquélla cuando el Estado ha sido condenado judicialmente al pago de una suma de dinero.

Justifica el Tribunal la diferencia de trato normativo existente en el hecho de que «No es la posición preeminente de la Hacienda Pública, personificación sectorial de la Administración, como titular de potestades y prerrogativas, el dato determinante del diferente tratamiento respecto de los intereses procesales en ejecución de las Sentencias, sino al contrario, la minusvalía derivada de los principios de legalidad y contabilidad pública a los cuales aparece sometida constitucionalmente, que condicionan su actuación y obstaculizan la agilidad de movimientos muy por bajo del nivel de los particulares en el ejercicio de su libertad (autonomía de la voluntad en el campo jurídico)» (F.J. ${ }^{\circ} 4^{\circ}{ }^{\circ}$ ).

Prosigue el máximo intérprete de nuestra Constitución sus argumentaciones señalando que «En definitiva, se produce siempre, haya o no consignación presupuestaria, una demora inercial o institucional achacable al sistema de garantías para el correcto manejo de los dineros públicos que se traduce en un procedimiento plagado de cautelas, en beneficio de todos, demora pues no imputable a la Administración como persona jurídica ni a sus agentes. No se trata de una tardanza caprichosa o arbitraria, sino que hinca su raíz en razones profundas de los intereses generales a los cuales ha de servir la Administración y en las características objetivables de ésta» (F.J. $\left.{ }^{\circ} 4^{\circ}{ }^{\circ}\right)$. A juicio del Tribunal «(...) No son iguales las situaciones de la Hacienda Pública y de los demás (...) El trato distinto se funda pues en elementos diferenciales muy consistentes, con una justificación objetiva y razonable que en ningún momento puede considerarse artificiosa o arbitraria ni, por tanto, discriminatoria. Tampoco es desproporcionada si se repara en que el incremento del rédito se fija en dos puntos, cifra no excesiva en términos absolutos ni, por tanto, discriminatoria».

Por su parte la STC 69/1996, de 18 de abril, se encargó de examinar, igualmente desde la perspectiva que ofrece el principio de igualdad, las diferencias normativas aparentemente existentes entre los particulares y la Hacienda Pública respecto a la determinación del dies a quo para el devengo de los intereses procesales. En el primer caso, siendo deudor cualquier ciudadano y acreedora la Hacienda Pública, se ha de tener en cuenta que, al amparo de aquello que disponía el art. 921.4. ${ }^{\circ}$ de la antigua Ley de Enjuiciamiento Civil de 1881, «Cuando la resolución condene al pago de una cantidad líquida ésta devengará intereses a favor del acreedor desde que aquélla fuere dictada en primera instancia hasta que sea totalmente ejecutada». Y, tratándose de la situación opuesta, esto es, pesando la obligación de pagar sobre la Hacienda, establecía el art. 24 del antiguo Real Decreto Legislativo 1091/1988, de 23 de septiembre, 
por el que se aprobaba el Texto Refundido de la Ley General Presupuestaria (TRLGP), que el devengo tendría lugar en el día en que fuere notificada la resolución judicial. No aclaraba sin embargo el citado precepto si dicha resolución era la de instancia o la dictada en vía de recurso ni, en consecuencia, si había de ser firme o no.

Finalmente el Tribunal terminó salvando la constitucionalidad del citado precepto siempre que el mismo resultase interpretado en el sentido de que «La resolución judicial a partir de la cual han de correr los intereses procesales a cargo de la Hacienda Pública es también la dictada en la primera instancia. La conclusión así obtenida respeta el principio de igualdad sin introducir discriminación alguna, pues no hay razón constitucionalmente relevante para justificar un distinto trato en el devengo del interés de demora, según la posición que ocupe la Hacienda Pública y sólo por ella» ${ }^{24}$.

¿Y cuándo prescribe el derecho a exigir el pago de las obligaciones reconocidas o liquidadas? Con carácter general a los cuatro años, salvo lo establecido por leyes especiales, y siempre que no fuese reclamado por los acreedores legítimos o sus derechohabientes. Dicho plazo habrá de computarse desde la fecha de notificación del reconocimiento o liquidación de la obligación, causando baja en las respectivas cuentas las obligaciones prescritas, previa tramitación del oportuno expediente (art. 25.1. b de la LGP).

\section{GESTIÓN DEL PRESUPUESTO DE INGRESOS}

Los comúnmente denominados derechos de cobro son definidos por el Documento núm. 2 («Derechos de cobro e ingresos») de la CNPCP como «Aquellos créditos actuales de la entidad frente a terceros, surgidos como consecuencia de acontecimientos pasados, en virtud de los cuales el deudor queda obligado a satisfacer a la entidad una determinada cantidad de dinero, en un momento concreto (vencimiento) y en las condiciones que se deriven de su soporte documental» 25 .

Adviértase que se trata de una definición que integra derechos de cobro presupuestarios y no presupuestarios. Y es que, tal y como tendremos oportunidad de precisar, el reconocimiento de un derecho de cobro representa el proceso por el cual se incorpora al balance un elemento que cumple con las características de la definición de derecho a cobrar.

Así las cosas, los derechos de cobro presupuestarios son aquellos que suponen un recurso para financiar el gasto presupuestario del Ente Local, pudiendo

\footnotetext{
24 En esta misma línea pueden consultarse además las SSTC 110 /1996, 113/1996 y 23/1997.

25 INTERVENCIÓN GENERAL DE LA ADMINISTRACIÓN DEL ESTADO (IGAE), «Derechos de cobro e ingresos», Documento número 2, Madrid, 1992, pág. 43.
} 
tener su origen en operaciones que generan ingresos, ser consecuencia de la creación de pasivos financieros, realizaciones de activos financieros o de enajenaciones de elementos del inmovilizado no financiero. En la mayoría de los casos estos derechos suelen registrarse en el momento en que se dictan los correspondientes actos de liquidación que los cuantifiquen, aplicándose simultáneamente al presupuesto en vigor, si bien es cierto que existen una serie de excepciones a este regla contenidas en el citado documento.

A la hora de analizar la gestión del presupuesto de ingresos de los Entes Locales hemos de aludir a la existencia de dos fases sucesivas o simultáneas: el reconocimiento del derecho y la extinción del mismo.

El reconocimiento del derecho constituye el acto que, conforme a la normativa aplicable a cada recurso específico, declara y liquida un crédito a favor del Ente público Local o de sus Organismos Autónomos. Dicho reconocimiento o liquidación de los derechos de naturaleza pública de la Hacienda Local se presenta por tanto como un acto que, lógica y jurídicamente, tiene lugar tras el nacimiento o adquisición de los derechos, produciéndose de conformidad con lo establecido en la específica normativa reguladora de cada uno de ellos.

Para poder reconocer un derecho de cobro han de cumplirse las siguientes condiciones. En primer lugar, que se tenga constancia de que se ha producido un acontecimiento que haya dado lugar al nacimiento del derecho de cobro. En segundo término, que el derecho de cobro tenga un valor cierto y determinado. $\mathrm{Y}$, finalmente, que el deudor pueda ser determinado.

Este reconocimiento de los derechos de cobro podrá efectuarse antes o en el mismo instante del cobro. De acuerdo con este criterio, siendo el reconocimiento del derecho previo al cobro estaremos ante la figura del ingreso de contraído previo, ya sea por recibo (como es el caso de la mayoría de los impuestos locales: Impuesto sobre Bienes Inmuebles, Impuesto sobre Actividades Económicas, etc.) o por ingreso directo (por ejemplo, la liquidación de una tasa sujeta a este mecanismo de liquidación). Por otro lado, si el reconocimiento del derecho se realiza en el mismo momento del cobro, estaremos en presencia de una declaración autoliquidada o autoliquidación (como es el caso de la autoliquidación de una tasa sujeta a este mecanismo), o bien ante la figura denominada «otras liquidaciones» (por ejemplo, la mayoría de los precios públicos).

De cara a efectuar su cuantificación ha de seguirse un proceso por el cual se determina la cantidad monetaria por la que aquellos han de incorporarse al balance. Generalmente, los derechos de cobro se cuantifican por el importe determinado en el acto liquidatorio correspondiente, existiendo no obstante diversas excepciones a esta regla.

Por su parte la extinción de los derechos de naturaleza pública de la Hacienda Local tendrá lugar por las causas previstas en la Ley 58/2003, de 17 de di- 
ciembre, General Tributaria (arts. 60 a 75), así como en la normativa reguladora de cada derecho, pudiendo producirse por su cobro en metálico así como en especie, o por compensación, en los casos previstos en las disposiciones especiales que resulten de aplicación.

Respecto de las extinciones de derechos por causas distintas a su cobro en metálico, en especie o por compensación, debe tenerse presente que las mismas son objeto de contabilización diferenciada, según se produzcan por anulación de la liquidación o, en el proceso de recaudación, por prescripción, condonación o insolvencia. Así lo establece, si bien refiriéndose a la Hacienda Pública estatal, el art. 80.3 de la LGP.

En relación con la anulación conviene precisar que los derechos de cobro sólo podrán anularse como consecuencia de la adopción de un acuerdo de anulación motivado, bien por la anulación de la liquidación de la que se deriven, bien por la insolvencia probada del deudor, la condonación o la prescripción de la deuda u otras causas legalmente establecidas.

Destaca especialmente la anulación de liquidaciones que ya hubieran sido cobradas, al suponer la obligación de devolver el importe percibido por las mismas. Como consecuencia del acuerdo de devolución que de tal anulación se derive habrá de producirse el registro de una obligación a pagar. Ahora bien, en ningún caso la concesión de aplazamientos o fraccionamientos en derechos a cobrar implica la anulación de tales derechos.

Por último, las devoluciones de ingresos se gestionan distinguiendo entre el reconocimiento del derecho a la devolución, que tendrá su origen en un ingreso indebido o en otra causa legalmente establecida, y el pago de la misma ${ }^{26}$.

\section{LIQUIDACIÓN Y CIERRE DEL PRESUPUESTO LOCAL}

Como es sabido la liquidación y el cierre del Presupuesto constituyen aquella operación contable realizada una vez finalizado el ejercicio con la finalidad de establecer el resultado de la gestión tributaria, determinando las obligaciones y los derechos pendientes al final del ejercicio presupuestario.

Dos son las principales cuestiones que deben ser acometidas en su regulación. De una parte, la fijación del plazo en que debe liquidarse el Presupuesto, determinando los derechos y obligaciones económicas que pueden imputarse al mismo. Y, de otra, el régimen jurídico y contable de los ingresos y gastos pendientes.

\footnotetext{
26 De conformidad con lo dispuesto por el art. 81 de la LGP, «En la gestión de devoluciones de ingresos se distinguirá el reconocimiento del derecho a la devolución, cuyo origen será la realización de un ingreso indebido u otra causa legalmente establecida, y el pago de la devolución». Por su parte el art. 221 de la LGT se encarga de regular el procedimiento para la devolución de ingresos indebidos.
} 
En relación con la primera de las cuestiones planteadas conviene tener presente que el conjunto de operaciones contables que implica la elaboración del estado de liquidación del Presupuesto se encuentra estrechamente vinculado con la anualidad en la ejecución presupuestaria o con el principio de especialidad presupuestaria en la vertiente temporal. Así las cosas, coincidiendo el ejercicio presupuestario con el año natural, deben imputarse al cierre presupuestario los derechos económicos liquidados durante el ejercicio, cualquiera que sea el período de que deriven, y las obligaciones económicas reconocidas hasta el fin del mes de diciembre, siempre y cuando correspondan a adquisiciones, obras, servicios, prestaciones o, en general, gastos realizados dentro del ejercicio y con cargo a los respectivos créditos.

Con cargo a los créditos del estado de gastos sólo podrán contraerse obligaciones derivadas de adquisiciones, obras, servicios y demás prestaciones o gastos en general realizados en el propio ejercicio presupuestario. Y aquellos créditos para gastos que el último día del ejercicio presupuestario no se hallen afectados al cumplimiento de las obligaciones ya reconocidas quedan anulados de pleno derecho, salvo que por norma de rango legal se disponga lo contrario o se esté ante alguno de los supuestos contemplados en el art. 58 de la LGP, que autoriza expresamente a incorporar a los correspondientes créditos de un ejercicio los remanentes de crédito del ejercicio anterior ${ }^{27}$.

Pues bien, tal y como establece el art. 191 del TRLRHL, el cierre y la liquidación de los Presupuestos de las Entidades Locales y de los Organismos Autónomos de ellos dependientes tiene lugar, en cuanto a la recaudación de derechos y al pago de obligaciones, el 31 de diciembre del año natural. En efecto, siendo ejecutados durante el año natural, el cierre y liquidación de los Presupuestos debe efectuarse, en cuanto a la recaudación de derechos y el pago de obligaciones, el 31 de diciembre del mismo año.

De este modo aquellos créditos para gastos que el último día del ejercicio presupuestario no se encuentren afectados al cumplimiento de obligaciones ya reconocidas quedan anulados de pleno derecho. Y, paralelamente, los derechos liquidados pendientes de cobro y las obligaciones reconocidas pendientes de pago quedan a cargo de la Tesorería de la Entidad Local.

Con carácter general el estado de liquidación del Presupuesto de los Entes Locales consta de las siguientes partes: la liquidación del presupuesto de gastos, la liquidación del presupuesto de ingresos y el resultado presupuestario.

\footnotetext{
27 Tampoco puede ser objeto de incorporación a ejercicios posteriores el remanente de crédito al final de cada ejercicio del Fondo de Contingencia de Ejecución Presupuestaria, tal y como establece el art. 15 del RDLeg. 2/2007, de 28 de diciembre, por el que se aprueba el Texto Refundido de la Ley General de Estabilidad Presupuestaria. Dispone concretamente el citado precepto en sus apartados $4 .^{\circ}$ y $5 .^{\circ}$ lo siguiente: «4. El Gobierno, a través del Ministro de Hacienda, remitirá a las Comisiones de Presupuestos del Congreso de los Diputados y del Senado y, para su conocimiento, un informe trimestral sobre la aplicación del Fondo de Contingencia de ejecución presupuestaria del trimestre inmediatamente anterior. 5. El remanente de crédito al final de cada ejercicio anual en el Fondo de contingencia de ejecución presupuestaria no podrá ser objeto de incorporación a ejercicios posteriores».
} 
La liquidación del presupuesto de gastos para el presupuesto de gastos del ejercicio que se cierra, con el nivel de desagregación del presupuesto inicialmente aprobado y sus posteriores modificaciones, ha de detallar los créditos presupuestarios iniciales, las modificaciones de los créditos presupuestarios, los créditos presupuestarios definitivos, los gastos comprometidos, las obligaciones reconocidas netas, los remanentes de crédito y las obligaciones pendientes de pago a 31 de diciembre.

Por su parte la liquidación del presupuesto de ingresos para el presupuesto de ingresos del ejercicio que se cierra, con el nivel de desagregación del presupuesto inicialmente aprobado y las posteriores modificaciones al mismo, debe detallar las previsiones presupuestarias iniciales, las modificaciones de las previsiones presupuestarias, las previsiones presupuestarias definitivas, los derechos reconocidos netos, la recaudación neta, los derechos cancelados y los derechos pendientes de cobro a 31 de diciembre.

Finalmente, por lo que respecta al resultado presupuestario, éste viene a poner de manifiesto las siguientes magnitudes. En primer lugar, el resultado presupuestario del ejercicio propiamente dicho, calculado por la diferencia entre los derechos reconocidos netos y las obligaciones reconocidas netas que se hubieren producido durante el ejercicio como consecuencia de operaciones no financieras y de activos financieros, indicando la incidencia de ambos componentes.

En segundo término, la variación neta de pasivos financieros obtenida como diferencia entre los derechos reconocidos netos y las obligaciones reconocidas netas por este tipo de operaciones. Por último, el resultado presupuestario refleja el saldo presupuestario del ejercicio como agregación del resultado presupuestario y de la variación neta de los pasivos financieros ${ }^{28}$.

En suma, como consecuencia de la liquidación se determinan los derechos pendientes de cobro y las obligaciones pendientes de pago a 31 de diciembre, además del resultado presupuestario del ejercicio, los remanentes de crédito y el remanente de Tesorería. Este último, el remanente de Tesorería de la Entidad Local, se encuentra integrado por los derechos pendientes de cobro, las obligaciones pendientes de pago y los fondos líquidos, todos ellos referidos al 31 de diciembre.

\footnotetext{
28 Téngase presente además que la aprobación en su día de la antigua Ley 18/2001, de 12 de diciembre, General de Estabilidad Presupuestaria, posibilitó, no ya sólo la utilización de nuevas técnicas destinadas a impedir la expansión del gasto público a través de las modificaciones de crédito, sino también la determinación de las consecuencias derivadas de las situaciones de déficit o superávit presupuestario. Y es que tal y como dispone en la actualidad el art. 11 del RDLeg. 2/2007, de 28 de diciembre, por el que se aprueba el Texto Refundido de la citada Ley, «Si cualquiera de los sujetos que integran el Sector público a efectos de esta Ley, incumpliendo las obligaciones en ella contenidas o los acuerdos que en su ejecución fuesen adoptados por el Ministerio de Economía y Hacienda o por el Consejo de Política Fiscal y Financiera de las Comunidades Autónomas, provocan o contribuyen a producir el incumplimiento de las obligaciones asumidas por España frente a la Unión Europea como consecuencia del Pacto de Estabilidad o Crecimiento, asumirá en la parte que le sea imputable las responsabilidades que de tal incumplimiento se hubiesen derivado».
} 
La confección de los estados demostrativos de la liquidación del Presupuesto ha de realizarse antes del primero de marzo del ejercicio siguiente, correspondiendo al Presidente de la Entidad Local, previo informe de la Intervención, la aprobación de la liquidación. Asimismo ha de darse cuenta al Pleno en la primera sesión que celebre y remitirse la correspondiente copia (antes de finalizar el mes de marzo) a la Comunidad Autónoma y a la Administración del Estado.

Es concretamente el art. 193.5 del TRLRHL el encargado de regular la obligación de éstas de remitir una copia de la liquidación de sus Presupuestos a la Administración del Estado antes de finalizar el mes de marzo del ejercicio siguiente al que corresponda. Se trata de una obligación que ha de ponerse en conexión con la contemplada en el art. 21 del Real Decreto Legislativo 2/2007, de 28 de diciembre, por el que se aprueba el Texto Refundido de la Ley General de Estabilidad Presupuestaria, en virtud de la cual el Ministerio de Economía y Hacienda podrá recabar de las Entidades Locales la información necesaria para permitir la verificación de la adecuación al principio de estabilidad presupuestaria, dentro de la que se incluyen datos propios de la cuenta general de la Entidad Local.

Ya en su día a través del Real Decreto 263/1996, de 16 de febrero, por el que se regula la utilización de técnicas electrónicas, informáticas y telemáticas por la Administración General del Estado, se trató de delimitar, en el ámbito de aquélla, las garantías, requisitos y supuestos de utilización de estas técnicas ${ }^{29}$. En efecto, con la finalidad de facilitar la transmisión de dicha información por parte de las Entidades Locales, el Ministerio de Economía y Hacienda procedió a crear una aplicación telemática en el portal de Internet del Ministerio de Economía y Hacienda accesible a través de la Oficina Virtual de Coordinación Financiera con las Entidades Locales. De este modo se procedió a diseñar el oportuno procedimiento para la presentación telemática de la liquidación de los Presupuestos y de la información adicional que las Entidades comprendidas en el ámbito de aplicación subjetivo del art. 2.1 d) RDLeg. 2/2007, de 28 de diciembre, han de suministrar al Ministerio de Economía y Hacienda, ofreciéndose asimismo la posibilidad de firmar electrónicamente los datos transmitidos.

En la actualidad ha de tomarse en consideración lo dispuesto en la Orden EHA/468/2007, de 22 de febrero, por la que se establecen las condiciones generales y el procedimiento para la presentación telemática de la liquidación de los Presupuestos de las Entidades Locales y de la información adicional requerida para la aplicación efectiva del principio de transparencia en el ámbito de la estabilidad presupuestaria. Quedan incluidas pues dentro del ámbito de aplica-

29 Concretamente dicho Real Decreto fue dictado en cumplimiento de lo establecido en el art. 45 de la Ley 30/1992, de 26 de noviembre, de Régimen Jurídico de las Administraciones Públicas y del Procedimiento Administrativo Común. Como seguramente se recordará, en dicho precepto se instaba a las Administraciones Públicas a promover el empleo y la aplicación de técnicas y medios electrónicos, informáticos y telemáticos destinados al desarrollo de su actividad y al ejercicio de sus competencias. 
ción de esta Orden las Entidades Locales, sus Organismos autónomos y los entes públicos dependientes de aquéllas que presten servicios o produzcan bienes que no se financien mayoritariamente con ingresos comerciales.

¿Cuáles son las condiciones previstas para la presentación telemática de la liquidación del presupuesto de las Entidades Locales, así como de la información económico-financiera adicional requerida? El necesario desglose informativo de la liquidación presupuestaria de dichas Entidades, así como los datos económico-financieros adicionales a suministrar en el marco de la estabilidad presupuestaria y de la contabilidad nacional, son incorporados anualmente a la aplicación telemática de captura de datos de la liquidación del presupuesto de aquéllas, publicada en la anteriormente citada Oficina Virtual de Coordinación Financiera con las Entidades Locales, integrada en el Portal de Internet del Ministerio de Economía y Hacienda. El acceso a la aplicación a través del sistema de autenticación establecido da paso así a una relación de cuestionarios adaptada al tipo y magnitud de la Entidad Local.

Ha de ser el Interventor o, en su caso, el titular del órgano de la Entidad Local que tenga atribuida la función de contabilidad, quien reciba de la Dirección General de Coordinación Financiera con las Entidades Locales los datos necesarios para su autenticación, los cuales permiten el acceso a la aplicación telemática de captura de datos de la liquidación del Presupuesto. Mediante esta autenticación, basada en la generación de un usuario y de una contraseña secretos, el Interventor o funcionario asimilado puede, a su vez, autorizar a otros funcionarios de la Entidad Local para que puedan introducir datos en la aplicación.

El Interventor puede optar por cualquiera de las siguientes posibilidades a la hora de transmitir los datos: transcribir manualmente los datos a los cuestionarios de la aplicación de captura de datos diseñada al efecto; importar los datos desde archivos con los formatos ofimáticos previstos al efecto, descargables desde la propia aplicación de captura de datos a las celdas de los cuestionarios respectivos; o utilizar el formato normalizado de archivo, basado en el estándar internacional XBRL (Extensible Business Reporting Language) para simplificar la automatización del intercambio de información financiera, disponible para su descarga en la propia aplicación.

La firma electrónica de los datos transmitidos por el Interventor exime de la obligación de remitir una copia legal en papel de la liquidación del presupuesto. Ahora bien, para poder llevarse a cabo el procedimiento telemático con firma electrónica es necesario el cumplimiento de los siguientes requisitos. En primer lugar, el firmante de los datos ha de ser siempre el Interventor o funcionario asimilado de la Entidad Local, sin que pueda delegar su firma.

En segundo término, el Interventor ha de disponer de un certificado electrónico de usuario Clase 2CA expedido por la Fábrica Nacional de Moneda y 
Timbre-Real Casa de la Moneda, debiendo contar además con un certificado de DNI electrónico expedido por la Dirección General de la Policía o con cualquier otro certificado admitido por el Ministerio de Economía y Hacienda que figure en la relación de los tipos de certificados electrónicos reconocidos, así como de los prestadores de servicios de certificación que los expiden ${ }^{30}$.

El Interventor ha de utilizar para la firma electrónica de los datos el componente de firma electrónica incluido en la aplicación de captura de datos de la liquidación del Presupuesto, el cual es desplegado sólo en el caso de que se active la utilidad de firma electrónica de los datos. La presentación telemática de datos firmados electrónicamente genera un asiento de entrada en el registro de la aplicación o en el registro oficial que proceda, dejando constancia tanto de la entrega como de la fecha y hora en que se produjo, a efectos del cómputo de plazos. Este asiento motiva el correspondiente acuse de recibo.

Y, finalmente, en el supuesto de que los datos fuesen transmitidos sin firma electrónica, se mantendría la obligación para la Entidad Local de la remisión de una copia en papel de la liquidación presupuestaria firmada por el Interventor o funcionario asimilado.

Debe precisarse no obstante que de cara a la realización de las cuentas provisionales de la Contabilidad Nacional a cargo de la Intervención General de la Administración del Estado se elabora una muestra de Entidades Locales. Aquéllas que resulten incluidas en dicha muestra han cumplimentar unos cuestionarios diseñados al efecto. Los datos que se obtengan deben ser anticipados telemáticamente en cuanto se disponga de una estimación razonable de los mismos. Y, a pesar de que no han de ser firmados electrónicamente, adquieren un carácter provisional, restringiéndose su uso por parte del Ministerio de Economía y Hacienda exclusivamente a aspectos estadísticos. En cualquier caso estos datos deben ser suministrados antes del 31 de marzo del año siguiente al que se refiera la información. Posteriormente, una vez aprobada la liquidación del Presupuesto, ésta se coteja con la información provisional, procediéndose a cumplimentar el resto de cuestionarios relacionados bajo el epígrafe «Datos definitivos de la Liquidación de los Presupuestos».

30 Dicha relación se encuentra publicada en el Portal de Internet del Ministerio de Economía y Hacienda (www.minhac.es). 